\title{
Situação De Rua e Abordagem Social: Desafios Operacionais ao SUAS
}

La Falta de Vivienda y Enfoque de Atención Social: Desafíos Operativos para el SUAS

Homelessness and Social Care Approach: Operational Challenges for SUAS

\section{Willian Maciel Krüger}

\section{Clarissa De Antoni}

Universidade Federal de Ciências da Saúde de Porto Alegre (UFCSPA), Porto Alegre, RS, Brasil

\section{Mateus Augusto Pellens Baldissera}

Universidade Federal do Rio Grande do Sul (UFRGS), Porto Alegre, RS, Brasil

\section{Resumo}

Uma vez revelada a complexidade das experiências biográficas de pessoas em situação de rua, é urgente o aumento do número de estudos que qualifiquem a relação prática entre usuárias/os, políticas públicas e a representação do Estado na execução dos serviços de proteção. Para esta discussão, adicionamos as idiossincrasias sócio-históricas acerca do fenômeno da situação de rua no Brasil e a sua relação com o funcionamento do Sistema Único de Assistência Social (SUAS). No intuito da expansão teórico-prática dessa problemática, este estudo objetivou relatar as experiências de trabalho psicossocial dentro do Estágio Profissional de Psicologia em um serviço de abordagem social no município de Porto Alegre, Brasil. Nossos resultados alocam alguns aspectos estruturais, sócio-históricos e biopolíticos como elementos que interferem na execução ótima dos serviços tipificados pelas políticas públicas, marcando a dissonância entre políticas e suas implementações nos serviços.

Palavras-chave: Situação de Rua; Assistência Social; Abordagem Psicossocial.

\begin{abstract}
Once the complexity of homeless people biographical experiences is unveiled, there is urgency in increasing the number of studies that qualify the practical relationship between users, public policies, and state representation within social protection. To this discussion we add the sociohistorical idiosyncrasies about the phenomenon of homelessness in Brazil and their relation with the Brazilian Public Social Care System (SUAS) functioning. In order to theoretical and pragmatically explore this problem, this study aimed at informing about psychosocial work experiences within the scope of professional psychology internship in a social care approach
\end{abstract}


service in Porto Alegre, Brazil. Our results allocate structural, socio-historical, and biopolitical aspects as elements that interfere with the optimal execution of governmental typified interventions, glossing the dissonance between policies and their implementation in public services.

Keywords: Homelessness; Social Care; Psychosocial Approach.

\section{Resumen}

Una vez revelada la complejidad de las experiências biográfico de las personas sin hogar, hay urgencia en aumentar el numero de estudios que califican la relación práctica entre las/os usuarias/os, las políticas públicas y la representación del Estado en la ejecución de servicios de protección. A esta discusión, agregamos las idiosincrasias sociohistóricas sobre el fenómeno de la falta de vivienda en Brasil y el relación con la funcionalidad del Sistema Único de Asistencia Social (SUAS). Para la expansión teórico-práctica de este problema, este estudio tuvo como objetivo informar sobre experiencias de trabajo psicosocial dentro de la pasantía de psicología profesional en un servicio de enfoque de atención social en la ciudad de Porto Alegre, Brasil. Nuestros resultados asignan algunos aspectos estructurales, sociohistóricos y biopoliticos como elementos que interfieren en la ejecución óptima de los servicios tipificados por políticas públicas, marcando la disonancia entre las políticas y sus implementaciones en servicios.

Palabras clave: Falta de Vivienda; Asistencia Social; Enfoque de Atención Psicosocial.

\section{Introdução}

Estima-se que no Brasil 101.000 pessoas vivem atualmente em situação de rua (Natalino, 2016). Apesar desse número expressivo, há projeção de defasagem para o valor. $\mathrm{O}$ perfil sociodemográfico e psicossocial aponta para uma considerável variabilidade étnica, de gênero e de faixasetárias (Kunz, Heckert \& Carvalho, 2014; Sicari \& Zanella, 2018), percebendo-se, ainda, heterogeneidade educacional, territorial e psicossocial para a população (Escorel, 2000).
Estudos deflagram a complexidade deste fenômeno em termos das densas redes interpessoais constituídas entre indivíduocomunidade-urbanização （Escorel， 2000; Balieiro, Soares \& Vieira 2017). As discussões científicas atuais sobre a temática superam, portanto, as marcas sóciohistóricas de investigação das/os moradoras/es na rua por uma ontologia taxonômica e normalizadora. Em um contrabalanço, orientam-se para a relação sistêmica da população com todas as estruturas sociais disponíveis ao seu contato, entendendo-a tanto a partir das suas 
potências quanto das suas vulnerabilidades (Kunz et al., 2014; Balieiro et al., 2017).

Dentro do prisma político, salientamos a complexidade técnica e organizacional do trabalho neste escopo. Um número considerável de entraves é vivenciado no cotidiano das atividades, principalmente pela falta de recursos federais, estatais e municipais para os serviços básicos de Assistência Social e Saúde e pela apropriação recente do Sistema Único de Assistência Social (SUAS) (Iamamoto, 2009).

Questionar a funcionalidade do serviço público fornecido ao grupo é questionar o próprio paradigma do morar da rua e a relação prática da/o usuária/o com a implementação da política nos serviços na ponta, observada empiricamente no dia-a-dia dos atendimentos. A discussão das implicações sociais, econômicas e políticas que levam o sujeito à vulnerabilização da rua-moradia é, portanto, extremamente vasta. Ainda que não passível de se esgotar por um número discreto de disciplinas, o corpo das ciências sociais e humanas deve, ao menos, atentar para as relações de poder e sua microfísica dentro do serviço socioassistencial, tocando os aspectos sociohistóricos e psicossociais relativos à construção da vulnerabilidade e da violência contra minorias (Bourdieu, 1998; Fanon, 2008; Mbembe, 2014; Foucault, 2014). Há, neste contexto, a oportunidade de diálogo entre a Psicologia, a Psicanálise Social, as Políticas Públicas e a Assistência Social.

Temos por objetivo, portanto, refletir sobre as aplicações das políticas do SUAS tocantes à proteção do sujeito em situação de rua. Nesta reflexão, a partir da análise interpretativa de um relato de experiência em um Serviço Especializado em Abordagem Social (SEAS) no município de Porto Alegre, integramos os aspectos sóciohistóricos, organizacionais e biopolíticos das instituições que prestam o atendimento para o grupo.

\section{A Inserção no Campo}

Este estudo se trata de um relato de experiência em um SEAS pertencente a um núcleo de trabalho conhecido como "território centro" - região composta por dez bairros na cidade de Porto Alegre, no estado do Rio Grande do Sul. A vivência em campo ocorreu entre fevereiro de 2019 e janeiro de 2020. A inserção ocorreu durante prática de estágio profissional do curso de Psicologia.

Durante este tempo foram desenvolvidas atividades no âmbito das funções de Técnico Social Psicólogo, 
tipificadas pelas Normas Operacionais de Recursos Humanos do SUAS - NOB/RHSUAS (Brasil, 2006). Além do contato com ações executadas dentro das dependências do serviço e no espaço da rua, houve o trânsito por outras instituições na instância Sistema Único de Assistência Social, além de órgãos do Sistema Único de Saúde (SUS), entidades do Ministério da Educação (MEC) e da Secretaria de Segurança Pública da cidade de Porto Alegre (SSP). Foram cumpridas $700 \mathrm{~h}$ de trabalho ao longo do ano. Durante a experiência, foram produzidos materiais de investigação próprios de etnografia (Lamnek, 1989), como diários de campo e coleção documental, além da observação participante. Para este artigo, promovemos análises interpretativas do material coletado a partir de levantamento bibliográfico (Lamnek, 1989) concernente ao tema de situação de rua, assistência social e vulnerabilidade.

Observamos que o SEAS está consolidado atualmente como serviço de linha de frente na proteção socioassistencial da população-chave, visto que sua operacionalização no município engloba também o acompanhamento social na modalidade "Serviço de Proteção e Atendimento Especializado a Famílias e Indivíduos” (PAEFI) (PMPA, 2006). Desta constatação, nossa análise se derivou para a investigação da constituição administrativa e técnica do serviço dentro dos órgãos de proteção social especial. Foram notados desafios ou lacunas operacionais nas intervenções que advêm propriamente do processo de construção social da situação de rua, sobretudo nos termos dos fatores de risco associados (Kunz et al., 2014). Para estruturar nossa discussão extraímos, portanto, dois eixos analíticos ligados às dinâmicas operacionais de trabalho no local.

Os eixos foram nomeados seguindo sua abrangência teórico-prática. Assim, iniciamos a sequência de análise pelos aspectos operacionais do atendimento psicossocial, abordando pontos da observação empírica da rotina de trabalho, fluxos organizacionais e tipificação política das intervenções com o grupo-chave. Em seguida, são expostos os aspectos biopolíticos da abordagem social, explorando, sobretudo, como as políticas e ações de trabalho são legitimadas, reificadas e transmitidas pelas entidades prestadoras de serviços e como isso se espelha no estigma vivido pela população dentro dos centros urbanos. 
Aspectos Operacionais do Ação Rua:

\section{Especificidades}

do

Atendimento

\section{Psicossocial}

A abordagem social para pessoas em situação de rua está prevista na Tipificação Nacional de Serviços Socioassistenciais (Warpechowski, 2018), inserida no campo da Proteção Social Especial de Média Complexidade. O serviço visa atuar com situações de trabalho infantil de crianças e adolescentes, além de adultos que se encontram em situação de rua-moradia. De acordo com essa Tipificação, o trabalho se dá no intuito da garantia de direitos, suprindo necessidades imediatas dessas pessoas, além de promover a articulação com a rede socioassistencial ou redes de outras políticas públicas, como saúde, habitação e justiça.

Cabe ressaltar que a atenção à população em situação de rua em Porto Alegre já acontecia desde meados de 1980, mas somente houve a oficialização da sua atuação com a construção do Projeto "Ação Rua", no ano de 2007. Mesmo antes da instituição do SUAS, Porto Alegre (seja por vias legislativas ou pela atuação de organizações da sociedade civil) já pensava e executava serviços para o grupo (Fontanive et al., 2017). Por essa marca histórica, ainda notamos reificação da representação assistencialista nos serviços da Proteção Especial no município (Iamamoto, 2009; Silva, 2015).

As atuações sócio-assistenciais desenvolvidas pela equipe, durante nossa experiência, buscavam contornar a representação assistencialista do serviço de abordagem, sem que houvesse perda ou prejuízo do vínculo com a/o usuária/o. Trabalhávamos com os sujeitos a impossibilidade de fornecermos diretamente recursos monetários para a sua situação mas tentávamos proporcionar outros elementos que possibilitassem o acesso à instituições protetivas (albergues, abrigos, entidades filantrópicas e restaurantes populares) e conhecimento sobre políticas públicas da Proteção Especial (encaminhamento para acolhimento institucional, acompanhamento em órgãos de representação jurídica como o Ministério Público, tentativa de obtenção de Benefício de Prestação Continuada, acesso a serviços de saúde, etc).

É relevante destacar que em 2016 houve um aumento das equipes do Ação Rua (SEAS), o que reordenou a dinâmica de trabalho: toda a abordagem passou a ser feita pelos núcleos parceirizados com o poder municipal e referenciados aos Centros de Referência Especializado de Assistência 
Social (CREAS), em caráter multigeracional. Dentro da interseccionalidade das ações, pela concepção interdisciplinar do projeto, percebemos a presença majoritária das disciplinas de Psicologia, Serviço Social e Pedagogia como saberes úteis à qualificação da interação sistêmica da/o usuária/o do serviço com diferentes estruturas sociais, tais como sua família, os espaços educacionais e os espaços de saúde (Warpechowski, 2018). A exemplo, quase todas/os as/os técnicas/os e educadoras/es sociais com quem convivemos durante a experiência de trabalho possuíam formação educacional relacionadas a estas disciplinas, em nível técnico ou superior.

Nossa experiência ocorreu em alinhamento às NOB/RH-SUAS (Brasil, 2006), dentro das funções competidas à/ao técnica/o social no SEAS, nas atividades relacionadas ao acompanhamento psicossocial das/os usuárias/os. Nossa posição, dentro da norma operacional, nos colocava como agentes responsáveis por organizar, otimizar e garantir a interface entre as/os usuárias/os e as redes de proteção assistenciais, prevendo técnicas de manejo psicossocial que fomentassem a aderência às ações do projeto e o acolhimento psicológico da população. No intuito de promover a adesão e o acolhimento, fazia parte da nossa lide entender os sujeitos em situação de rua como seres autônomos, integrados a diferentes instâncias sociais (Warpechowski, 2018) e pertencentes a uma rede orgânica de convivência, com seus pares, a sociedade civil e o próprio espaço público (Rosa, 2016).

Conhecimentos teóricos sobre as especificidades da vivência na rua orientavam as nossas práticas, essenciais à pragmática do atendimento psicossocial com grupo. Esse tipo de levantamento demográfico e síntese teórica - e.g., o entendimento psicodinâmico de transtornos mentais e doenças crônicas prevalentes, abuso de substâncias psicoativas, dinâmicas e conflitos específicos da faixa desenvolvimental da/o usuária/o e possíveis dinâmicas de uso do espaço urbano (Botti et al., 2010; de-Antoni \& Munhós, 2016) eram úteis para delinearmos, minimamente, uma tipologia de intervenção e, disto, agilizar os processos de vinculação (Rosa, 2016).

Nossos atendimentos e acompanhamentos designavam os processos de desenvolvimento, auxílio e incentivo do acesso às políticas públicas do grupo: uma vez que estabelecíamos o vínculo e entendíamos em parte a biografia dos 
sujeitos, traçávamos, juntos com a/o usuária/o, um plano de acompanhamento longitudinal. Dentro do acompanhamento, vivíamos alguns desafios inerentes às intervenções psicossociais para população com um perfil de vulnerabilidade tão agravado (Warpechowski, 2018).

Uma vez que a ação com a/o usuária/o está condicionada (em grande medida pela técnica de intervenção psicossocial) à construção da motivação para enfrentamento e diminuição das vulnerabilidades (Mendes \& Machado, 2004), possuíamos desafios na mobilização do desejo das/os usuárias/os em aderir ao trabalho com as equipes (Rosa, 2016). Era extremamente recorrente o recuo ou abandono das intervenções. A tolerância e o entendimento do "tempo" próprio das/os usuárias/os foi um elemento fundamental para a organização das ações e a solidificação da boa relação com as/os profissionais. $\mathrm{O}$ relato de diário de campo de um dos atendimentos, abaixo, sintetiza em partes esses aspectos:

Sérgio (pseudônimo), homem de 45 anos, negro e morador de rua há mais de 30 anos, apareceu ontem na frente da instituição, muito alcoolizado. Eu (estagiário) e ele temos tido atendimentos semanais há mais ou menos 5 meses. Sérgio demonstra um bom vínculo comigo. Quando eu o recebo, ele fala que não "aguentava mais", que estava "cansado" da vida nas ruas. Conversamos por aproximadamente uma hora. No meio do atendimento, muito emocionado, me entrega dois "pinos" de cocaína e uma garrafa de bebida alcóolica. Diz que não quer mais usar essas substâncias. No final da interação, já mais calmo, me diz que a conversa tinha lhe feito bem. Convido-o para irmos, então, a um Centro de Atenção Psicossocial (CAPS), familiar ao usuário. Justifico minha sugestão. Sérgio se mostra disposto. Já é a quarta ou quinta vez desse ano que ele aceita iniciar atendimento no local. Em todas as outras vezes, acabou desistindo. Propomos sair às $18 \mathrm{~h}$. Ele diz que podemos sair nesse horário, mas que antes precisará deixar pertences de maior valor com um amigo, próximo do local onde estávamos. Proponho que fiquemos conversando até a hora de sair, pois 
faltava pouco tempo. Ele reluta e prefere levar os objetos, mas diz que não devo me preocupar, porque ele retornará pontualmente às $18 \mathrm{~h}$. Sérgio não retorna no horário combinado. Já era final do meu expediente, mas resolvo aguardar mais uma hora. Ele não aparece. Decido ir embora. Inicialmente me tomo de culpa e frustração por não ter conseguido convencê-lo a ficar. No outro dia descubro que Sérgio teria retornado horas depois do combinado mas que, mesmo com o atraso, teria ido ao CAPS sozinho (Diário de Campo, setembro de 2019).

Episódios como esse demonstravam a variabilidade e a inconstância dos planos de acompanhamento com o grupo. Ficava claro, ainda, que o elemento de maior importância no processo de atendimento com a população em situação de rua era o fortalecimento da relação vincular entre a/o técnica/o e a/o usuária/o. A vinculação se tornava elemento que proporcionava sensibilização ao "tempo lógico" do sujeito sobre seu empoderamento e tomada de desejo. Sobre isso, Rosa (2016) discute a noção de "responsabilidade" e "responsabilização" do sujeito na clínica psicossocial. Diz a autora:

Entendemos responsabilidade
como o compromisso do sujeito e
do campo social com as leis
construídas para gerir o campo
social, assim como com as
respostas à lei. Já a
responsabilização refere-se ao
exercício ético/político de
posicionar-se no laço social
sustentando um pacto que garante
não só a contenção de excessos,
mas também um lugar para a
alteridade e diferença. (Rosa, 2016
p. 139).

A perspectiva de garantir "alteridade e diferença" é uma marca importante no trabalho com a população. As intervenções, dentro das "tortuosidades" inerentes ao trabalho com a vulnerabilidade e a falta de recursos financeiros, demandam um senso de "responsabilização salutar" para a/o moradora/- de rua (Rosa, 2016). Isso não significa relativizar ou desmerecer as práticas psicossociais e as suas perspectivas de efetividade, mas criar um espaço de tolerância e continência em relação ao tempo do próprio sujeito. Consiste em um exercício 
pela/o usuária/o de perceber o seu desejo durante os momentos de narração biográfica e escuta psicossocial (Silva, 2015) e a manutenção desse processo ao longo dos acompanhamentos.

Ainda sobre a noção de escuta, trazemos a peculiaridade da escuta psicossocial em ambientes não controlados, de setting mutável. Dentro das especificidades da nossa atuação, ações no espaço da rua representavam a construção de espaços de fala e escuta dentro do contexto de vivência do sujeito (Maynart, Albuquerque, Brêda \& Jorge, 2014). Para além do valor simbólico dessa tipologia de setting, tínhamos o desafio de nos adaptar às adversidades e variabilidades dos espaços. Perturbações sonoras e visuais, ambientes de violência, grande fluxo de pessoas, presença de animais ou membras/os externas/os durante as conversas, entre muitos outros aspectos, exigiam olhar holístico às cenas de atendimento e uma forte percepção adaptativa às/aos técnicas/os: quando, $\underline{\text { como }}$ e até onde poderíamos aprofundar os tópicos dos atendimentos e utilizar os elementos (simbólicos) ao nosso redor como fatores de potencialização das intervenções eram os principais desafios do trabalho nesse escopo. Notadamente, percebemos que há necessidade de aperfeiçoamento técnico e teórico das intervenções psicossociais pelas disciplinas atuantes nos serviços do SUAS, especialmente para a Psicologia (Mendes \& Machado, 2004).

Aspectos Biopolíticos do Serviço de Abordagem: Vulnerabilidade, Coerção e Gestão da Miséria

Em uma apreciação global do serviço de Abordagem Social no município, ainda que reconheçamos que as suas normas operacionais estão em consonância a um modelo técnico e científico de intervenção com populações em situação de vulnerabilidade social, foram percebidas algumas problemáticas na execução das atividades. Todas adentram características epistemológicas constitutivas do trabalho nesse escopo e da própria constituição da rua-moradia como um problema para o Estado (Kunz et al., 2014). A complexidade sociológica desse campo no Brasil constitui, senão, uma laminação própria do serviço de assistência social (Iamamoto, 2009).

Surgem, portanto, algumas lacunas operacionais a serem discutidas no SEAS, também como um exemplo de outras falhas nas ações no âmbito do SUAS. Aspectos estruturais como preconceito, violência de gênero e preconceito racial foram notados 
como elementos constituintes da interação entre servidoras/es e usuárias/os. Durante a vivência em campo ou em reuniões de equipe presenciamos, por vezes, falas LGBTfóbicas, racistas e/ou misóginas pelas/os trabalhadoras/es:

Ah, a Regina (pseudônimo) [mulher negra, 30 anos, em situação de rua e vítima de abuso sexual] sempre que vem aqui fica dando em cima dos técnicos e educadores. Acho isso muito engraçado (risos)... ela não toma jeito. Ela tem um comportamento muito infantil. (Diário de Campo, abril de 2019).

Nos termos das ações próprias executadas pelo SUAS e das demais parcerias com a Saúde e Educação, percebemos a fragilidade de intervenções em alguns programas de moradia e garantia de renda - a exemplo de ações como o Projeto Mais Dignidade e Moradia Primeiro (PMPA, 2017), largamente exploradas pelas equipes no Ação Rua. Percebemos que estes projetos não contavam com verbas e planejamento suficientes para garantir controle e qualidade das ações para suposta superação da situação de rua. Os espaços fornecidos às/aos usuárias/os (apartamentos, casas e pensões, em diferentes pontos da cidade) se encontravam em precarizadas condições de conservação e salubridade. Além disso, faltavam móveis em seu interior e os critérios de higienização e segurança frequentemente eram corrompidos. Fora os problemas materiais, as localizações das residências eram em zonas de comércio e circulação de drogas, havendo a incongruência com o perfil de beneficiária/o do programa.

Tanto a institucionalização do preconceito quanto a precarização dos programas socioassistenciais inauguram um lugar de reconhecimento jurídico para a/o moradora/- de rua como um sujeito que vive entre restos (Baldissera, 2019). Faz-se útil, portanto, como ponto de sensibilização, o reconhecimento da existência nesses serviços, e a sua posterior caracterização, da violência simbólica presente nas ações.

Essa violência emerge como elemento ligante entre serviço e usuária/o: sem as violências às quais são expostos as/os usuárias/os, não se legitima a existência do serviço de abordagem social, pelo menos dentro da perspectiva da gestão política do Estado. A hierarquização tácita entre servidora/- e usuária/o denota o (grande) sentido para a ação da/o servidora/-. Este 
paradoxo desenha, ainda, um parâmetro de mensuração do desgaste laboral aos quais são expostos as/os trabalhadoras/es, uma vez que trabalhar a/contra a vulnerabilidade da/o outra/o é, por dualidade, uma situação de confronto com os próprios privilégios sociais ou reedição das próprias situações de violência experienciadas (Rosa, 2016). É, senão, o lugar do privilégio como ponto de diferenciação entre a "população em ruamoradia" e o "sujeito de direito".

Chamamos a atenção, ainda, para a regulação do Estado sobre a atividade do grupo e a sua limitação pelo uso da força militar coercitiva. Muitas vezes observamos remoções das pessoas em situação de rua por ordem policial. Nesse ínterim, o serviço da guarda agia a partir de solicitações de remoção vindas da sociedade civil. Lamunier (2019) destaca a existência de um patrimonialismo constitutivo da sociedade brasileira e a sua relação com a construção econômica do país como um modelo liberal, representativo e semi-democrático de administração financeira. Nessa situação, a figura do exército (autoritária) funcionaria como entidade protetiva dos bens da camada social privilegiada (e, portanto, politicamente atuante). As ações de remoção se davam, sob esse viés de análise, com justificativa de preservação do patrimônio público. Segue um exemplo extraído dos diários de campo:

A prefeitura ligou ontem para a instituição e disse que tínhamos $24 \mathrm{~h}$ para avisar todas/os as/os usuárias/os que ocorreriam remoções em massa no dia seguinte, no espaço do "talude" [região do município com alta densidade de pessoas em situação de rua]. Nas últimas três semanas, teríamos notado uma maior frequência de solicitações pelo canal de comunicação da prefeitura para a retirada dos sujeitos do local. Passado o período, na manhã próxima, fomos ao endereço prestar auxílio às/aos moradoras/es que haveriam perdido, por algum motivo, o aviso das equipes no dia anterior. Surpreendentemente ainda existia um número considerável de pessoas. A Polícia Militar e a Guarda Municipal, junto do Departamento Municipal de Limpeza Urbana, chegaram violentamente. Praticamente arrancaram as pessoas de dentro das suas residências e colocaram todos os seus bens no caminhão de 
lixo urbano. Algumas/ns usuárias/os ficaram atordoadas/os. Outras/os agiam com calma e estranha familiaridade. Era unânime e visível, contudo, o seu sentimento de revolta, seco e desamparado. Essas pessoas não teriam vagas garantidas em espaços de moradias emergenciais. Simplesmente deveriam procurar outros espaços urbanos para rehabitar, cada vez mais periféricos. (Diário de Campo, outubro de 2019).

Em consonância às ações coercitivas, a própria política de "combate" ao uso de drogas e redução de danos se transformava em uma via de exercício de poder em relação à população, sobretudo no controle das suas subjetividades (Bastos, 2019). Isso era visível pelo uso, muitas vezes não refletido, de internações compulsórias em instituições psiquiátricas e determinações de plano terapêuticos poucos flexíveis. Ao longo da nossa atuação presenciamos, pelo menos, 30 solicitações de internações compulsórias. Incongruentemente algumas eram solicitadas sem necessidade ou, quando necessárias, não eram utilizadas pela equipe.
Nesse perímetro, o trabalho na assistência social exerce uma dupla função nos serviços de proteção especial. Explorando o que Bourdieu (1998 cf. Serafino \& Luz, 2015) chama de "mão esquerda" e "mão direita" do Estado, enquanto as ações no perímetro da assistência social visam à reintegração do sujeito no âmbito de trocas simbólicas e sociais - a "mão esquerda", distributiva e assistencial, que em primeira medida representa o acesso às redes de proteção $\mathrm{e}$ garantia de direitos humanos - por outro expõe a/o moradora/- de rua ao mundo do trabalho e da sociedade jurídica e, com isso, às dinâmicas de vulnerabilização, normalização e exclusão típica à falta do capital dentro de um sistema político garantido pelo lucro e pela propriedade aspectos relacionados à "mão direita", responsável pela introjeção da lei social e do controle civil. Há escancarado poder da sociedade civil (classe detentora da propriedade) para solicitar remoções e restringir direitos da/o moradora/- do espaço da rua.

Se a política pública não garante uma reestruturação global ao sujeito em ruamoradia (demonstrada pelo acesso total à educação, saúde, habitação, renda e segurança), não há forma de garantir um 
espaço suficientemente protetivo para a/o usuária/o "alvo" de ações parciais ou fragmentadas, sobretudo após sua reinserção no mundo do trabalho. A realidade do serviço, nesse paradigma, não se alinha visivelmente às exigências ampliadas do sujeito nessas condições. Certamente o estigma encarnado nos marcadores sociais da população serão elementos de retroalimentação de suas violências.

Esses pontos tocam elementos de biopolítica estatal e gestão de recursos públicos (Foucault, 2014). Sobre a gestão de recursos, ainda preferimos chamar de gestão da miséria todo processo de manipulação da vulnerabilidade social, que de maneira elíptica retroalimenta o sistema de violências e opressão simbólica, privilegiando, a partir de restos, uma parcela da população vulnerável ou reparando parcialmente o todo vulnerabilizado.

Frequentemente foram observadas cenas de escolha de usuárias/os que deveriam ser, ou não, contempladas/os com alguma política de benefício assistencial (de moradia, saúde, alimentação ou transporte). Esse ato se justificaria pela inexistência de recursos financeiros suficientes para todas/os dentro da máquina pública (Warpechowski, 2018). Atentamos, neste ínterim, ao ato de escolha como uma implicação ética da gestão da miséria: selecionar as pessoas mais vulnerabilizadas entre o todo de uma população violentada. É, senão, o biopoder no seu âmago, especialmente quando pensamos o "direito sobre a vida e proibição da morte" enquanto parâmetros técnicos de muitas intervenções socioassistenciais. Há nesse processo a escolha daquela/e que terá mais chance de resistir e suceder no mundo do capital.

É por meio da análise da gestão da miséria que identificamos muitos elementos da biopolítica de Estado relacionadas à vulnerabilidade social. Foucault (2003) discute os mecanismos disciplinatórios e regulatórios como formas de controle dos corpos e das subjetividades, no âmbito da normalização das práticas sociais, da violência e, senão, da própria representação social do que chamamos de "sujeito" (tanto na perspectiva individual, de pessoa, quanto na perspectiva social, de população). No âmbito das trocas simbólicas e sociais, a ideia do sujeito de direito perpassa a figura do homem branco e detentor da propriedade, enquanto a população de rua, majoritariamente negra e desprovida do acesso aos bens de consumo, representa a figura abjeta ao estilo de vida do chamado “cidadão de bem" (Fanon, 2008; Mbembe, 2014). Ao longo de todos os relatos expostos 
neste trabalho, por exemplo, percebemos elementos da vilanização da/o moradora/- de rua como aquela/e capaz de roubar, matar e/ou exonerar os bens públicos em troca de pouco ou nenhum retorno social.

Esse modelo de racismo de Estado (Foucault, 2003) ou bioeconomia racial (Mbembe, 2014) justifica a necessidade do extermínio e vilipêndio (i.e., ações disciplinatórias) ou da normalização da vulnerabilidade e da desigualdade social (i.e., ações regulatórias) sob o corpo dos sujeitos em situação de rua. O racismo de Estado é causa, e ao mesmo tempo consequência, das "guerras" contra a criminalidade e aquilo que supostamente ofende o modelo de bem-estar social moderno (como, por exemplo, a "guerra" ao crime, o "combate" às drogas, a "erradicação" da miséria, etc) (Foucault, 2003).

Não podemos deixar de apontar, ainda, que esse mesmo modelo belicista e autoritário de bem-estar social cria, senão, um arquétipo de violência como um fenômeno que deve ser individualizado e fantasticamente eliminado pelo poder soberano (branco e patriarcal) do Estado. Podemos hipotetizar que o conjunto desses fatores de opressão proporciona certa postura contrafóbica da camada detentora da propriedade ao excluir e abjetificar a população em situação de rua na completude de todos os seus marcadores sociais, sobretudo pela cor da sua pele (Fanon, 2008). A ética da gestão da miséria explicita, de forma prática e virtual, a biopolítica por epítome (Foucault, 2014). Pela nossa experiência, notamos que ser um sujeito de direito (um sujeito jurídico, portanto) nesse contexto importa muito mais pelo símbolo de moralidade que representa à sociedade civil do que a tentativa pura da superação da desigualdade social.

\section{Considerações finais}

Ao relatarmos as vivências em um serviço de abordagem social para população em situação de rua no município de Porto Alegre, em contraste à sua caracterização dentro da política socioassistencial do SUAS em âmbito das três esferas, debruçamo-nos sobre alguns aspectos sócio-históricos e organizacionais que impactam a qualidade das intervenções nessas instituições. $\mathrm{O}$ processo recente de consolidação da assistência social como uma política de Estado ainda apresenta restos de uma etiologia assistencialista, oligárquica e filantrópica, o que implica certa figuração moral, problemática, dentro das equipes de 
abordagem. Notamos, todavia, a presença do olhar técnico e metodologicamente sustentado em algumas ações das equipes, o que concretamente promove saúde e proteção ao grupo abrangido pelo projeto.

Em contrapartida, a violência simbólica, a gestão da miséria (dentro da falta de recursos públicos no equipamento do SUAS) e a biopolítica de vida e morte sobre a população, materializados por ações judiciais coercitivas, descrevem parte das dinâmicas que atuam negativamente nesses locais. A qualificação dos serviços oferecidos ao grupo implica na adequação metodológica das intervenções às características genealógicas do serviço e às diferentes tipologias de usuárias/os. Nesta delimitação, fluxos operacionais e organizacionais deverão ser revistos, tanto nos termos concretos da universalidade das ações executadas, quanto pela (não) presença do Estado como figura central e democrática na abordagem social.

No tocante à experiência vivida no local, destacamos o crescente protagonismo da Psicologia nos trabalhos sócioassistenciais. A prática profissional representou uma mudança paradigmática para o estagiário sobre a ontologia e as metodologias de atendimento fornecidas, contemporaneamente, pela Psicologia Social e Psicologia Clínica. A interface das/os agentes com corpos técnicos e teóricos no estudo da clínica e manejo do trauma e da vulnerabilidade, a partir de uma visão racializada e decolonial de Psicanálise e Psicologia Social, demonstra-se condição fundamental para o estabelecimento ótimo da Psicologia no trabalho com população em situação de rua.

\section{Referências}

Baldissera, M. (2019). Entre restos há quem sonhe: sobre a escuta psicanalítica com pessoas em situação de rua. (Dissertação de Mestrado). UFRGS, Rio Grande do Sul, Porto Alegre, Brasil. Recuperado de: https://lume.ufrgs.br/handle/10183/200 $\underline{318}$

Balieiro, E., Soares, C. \& Vieira, E. (2017). Morador de rua: causas, entraves e serviços ofertados. Temporalis, 17(34), 333-353. DOI: $10.22422 / 2238-$ $\underline{1856.2017 \mathrm{v} 17 \mathrm{n} 34 \mathrm{p} 333-353}$

Bastos, F. I. (2019). Políticas de drogas no Brasil contemporâneo: aportes da ciência, da clínica e do liberalismo moderno. Cadernos de Saúde Pública, $35(11), \quad 1-5$. DOI: $10.1590 / 0102-$ $\underline{311 \times 00125519}$

Botti, N. C. L., Castro, C. G., Silva, A. K., Silva, M. F., Oliveira, L. D., Castro, A. C. H. O. A. \& Fonseca, L. L. K. (2010). Avaliação da ocorrência de transtornos mentais comuns entre a população de rua de Belo 
Horizonte. Barbaroi, (33), 178-193. DOI: $\underline{10.17058 / \text { barbaroi.v0i0.1583 }}$

Brasil. (2006). Norma Operacional Básica de Recursos Humanos do SUAS NOB-RH/SUAS. Brasília, DF: MDS. Recuperado de: https://www.mds.gov.br/webarquivos/ publicacao/assistencia_social/Normati vas/NOB-

RH_SUAS_Anotada_Comentada.pdf.

Bourdieu, P. (1998). Contrafogos. Rio de Janeiro: Zahar.

De-Antoni, C. \& Munhós, A. A. R. (2016). As violências institucional e estrutural vivenciadas por moradoras de rua. Psicologia em Estudo, 21(4), 641-651. doi: $\underline{10.4025 / p s i c o l e s t u d . v 21 i 4.31840}$

Escorel, S. (2000). Vivendo de teimoso: moradores de rua da cidade do Rio de Janeiro. In: Bursztyn, M. (org.). No meio da rua: nômades, excluídos e viradores (pp. 139-171). Brasília: Garamond.

Fanon, F. (2008). Pele negra, máscaras brancas. Salvador: EDUFBA.

Fontanive, A. L., Oliveira, A. S. P. de., Santos, C. P. dos; Santos, D.; Bianchi, D., Canabarro, D., ...; Vieira, S. (2017). Experiências da ação na rua: da abordagem ao encontro. In: P. Schuch, I. Gehlen, \& S. R. dos Santos (Orgs.). População de rua: políticas públicas, práticas e vivências. Porto Alegre: CirKula.

Foucault, M. (2003). 17 March 1976. In: M. Foucault. Society must be defended (pp. 239-264). New York: Picador.
Foucault, M. (2014). Microfísica do Poder. (28 ed). São Paulo: Paz e Terra.

Kunz, G. S., Heckert, A. L. \& Carvalho, S. V. (2014). Modos de vida da população em situação de rua: inventando táticas nas ruas de Vitória/ES. Fractal: $\quad$ Revista de Psicologia, 26(3), 919-942. DOI: 10.1590/1984-0292/1192.

Iamamoto, M. V. (2009). O Serviço Social na cena contemporânea. Serviço Social: Direitos Sociais e Competências Profissionais. Brasília: CFESS/ABEPS, pp. 15-50. Recuperado de: http://www.abepss.org.br/arquivos/ane xos/o-servico-social-na-cenacontemporanea201608060403123057450.pdf

Lamnek, S. (1989). Qualitative Sozialforschung Band 2: Methoden und Techniken. Munich: Psychologie Verlags Union.

Lamounier, B. (2019). Bases do autoritarismo revisitado: diálogo com Simon Schwartzman sobre o futuro da democracia brasileira. In: Schwartzman et al. (orgs.). $O$ Sociólogo e as Políticas Públicas: Ensaios em Homenagem a Simon Schwartzman (pp. 53-66). Rio de Janeiro: Editora FGV.

Maynart, W. H. C., Albuquerque, M. C. S., Brêda, M. Z. \& Jorge, J. S. (2014). A escuta qualificada e o acolhimento na atenção psicossocial. Acta Paulista de Enfermagem, 27(4), 300-304. DOI: $\underline{10.1590 / 1982-0194201400051 .}$.

Mbembe, A. (2014). A Crítica da Razão Negra. Lisboa: Antígona. 
Mendes, A. A. \& Machado, M. F. (2004). Uma clínica para o atendimento a moradores de rua: direitos humanos e composição do sujeito. Psicologia ciência e profissão, 24(3), 100-105. DOI: $\quad 10.1590 /$ S1414$\underline{98932004000300013 .}$.

Natalino, M. A. C. (2016). Estimativa da população em situação de rua no Brasil. Texto para Discussão - IPEA. Recuperado de: https://www.ipea.gov.br/portal/index.p hp?option $=$ com_content\&view $=$ article $\underline{\text { \&id }=28819}$

Prefeitura Municipal De Porto Alegre (PMPA). (2006). Projeto Ação Rua. Porto Alegre, RS: Fundação de Assistência Social e Cidadania. Recuperado de: http://lproweb.procempa.com.br/pmpa/ prefpoa/fasc/usu_doc/acaoruaversaofin al2006_1.pdf.

Prefeitura Municipal De Porto Alegre (PMPA). (2017). Lei $n^{o}$ 19.885. Porto Alegre, RS: Legislação Municipal de Porto Alegre. Recuperado de: http://www2.portoalegre.rs.gov.br/neta $\underline{\mathrm{html} / \mathrm{sirel} / \text { atos/Decreto\%2019885 }}$

Rosa, M. D. (2016). A clínica psicanalítica em face a dimensão sociopolítica do sofrimento. (Tese de Doutorado). USP/Fapesp, São Paulo capital, Brasil. Recuperado de: https://psicanalisepolitica.files.wordpre ss.com/2014/06/psicanc3allisecultura-e-polc3adtica-livre-docenciamaio-2015impresso.pdf

Silva, M. M. (2015). Assistência social na realidade municipal: o SUAS e a prevalência conservadorismo. Revista

Katálysis, 18(1), 41-49. DOI: $\underline{10.1590 / 1414-49802015000100005}$

Serafino, I. \& Luz, L. C. X. (2015). Políticas para a população adulta em situação de rua: questões para debate. Revista Katálysis, 18(1), 7485. $\quad$ DOI: $\quad 10.1590 / 1414-$ 49802015000100008.

Sicari, A. A. \& Zanella, A. V. (2018). Pessoas em Situação de Rua no Brasil: Revisão Sistemática. Psicologia: Ciência e Profissão, 38(4), 662-679. DOI: $10.1590 / 1982-3703003292017$

Warpechowski, M. B. (2018). Adolescência, vulnerabilidade $e$ desamparo. Curitiba: Juruá.

Willian Maciel Krüger é diplomando em Psicologia da Universidade Federal de Ciências da Saúde de Porto Alegre (UFCSPA) e atua como pesquisador no Grupo de Pesquisa em Ciências da Linguagem - GPCL (UFCSPA).

E-mail: willian.mk83@gmail.com

ORCID:http://orcid.org/0000-0001-7796$\underline{2556}$

Mateus Augusto Pellens Baldissera é mestre em Psicanálise Clínica e Cultura pela Universidade Federal do Rio Grande do Sul e graduado em Psicologia pela Universidade Regional do Noroeste do Estado do Rio Grande do Sul. Atualmente é coordenador adjunto do Serviço Especializado em Abordagem Social (Ação Rua) e psicanalista em consultório particular.

E-mail: mateusbaldissera@gmail.com ORCID:http://orcid.org/0000-0003-3706$\underline{3817}$ 
Clarissa De Antoni é doutora em Psicologia do Desenvolvimento (UFRGS) e mestre em Psicologia (UFRGS), Especialista em Psicologia Social e Graduada em Psicologia. Atualmente coordena dois projetos de extensão nas áreas de violência contra a mulher e de prevenção ao suicídio em crianças e adolescentes.

E-mail: clarissadeantoni@gmail.com

ORCID:http://orcid.org/0000-0003-4521$\underline{9148}$

Submissão: 06/07/2020

$1^{\circ}$ avaliação: $24 / 08 / 2020$

Aceite: $21 / 10 / 2020$ 